\title{
A COMPARATIVE STUDY ON FEEDING OF TOTAL MIXED RATION VS CONVENTIONAL FEEDING ON WEIGHT GAIN IN WEANED FRIESIAN HEIFERS UNDER TROPICAL ENVIRONMENT
}

\author{
N.P.C.Nissanka ${ }^{1}$, R.M.A.S.Bandara ${ }^{1}$ and K.G.J.S.Disnaka ${ }^{2}$
}

\begin{abstract}
The study was carried out by using eighteen post weaned Friesian heifers (111.05 \pm 9.2 day old and weighing $96.6 \pm 8.4 \mathrm{~kg}$ ) to determine the effect of Total Mixed Ration (TMR) feeding system based on Wet brewer's grain, Kikuyu grass, commercial pellet feed and commercial Mineral Mixture on daily weight gain in Friesian heifers. Nutritional composition of each feed ingredient was proximately analyzed and the ration was formulated according to the recommended nutritional requirement of a weaned dairy heifer (NRC 2001). One group was fed with TMR feeding system and the other group was fed with conventional feeding system as a control. Weight gain was measured weekly of each animal under each treatment. Throughout the experimental period ( 8 weeks), the average daily weight gain (ADG) was $0.55 \mathrm{~kg} / \mathrm{d}$ in the treatment group and it was $0.33 \mathrm{~kg} / \mathrm{d}$ in the control group. ADG was significantly different in between these two groups at $p<0.009$.
\end{abstract}

Key Words: Average daily gain (ADG), Total Mixed Ration (TMR), Weaned heifers, conventional feeding system.

\section{INTRODUCTION}

Well grown heifers are the best foundation stock of a dairy herd. But in many farms, heifers become the most neglected group which leads to a poor growth rate and age at first calving greater than 24 months. The main objective of heifer rearing program is to be achieved appropriate body weight (300kg in Friesian breed) at the breeding age and attaining $1^{\text {st }}$ calving at 24 month of age. There are few major factors affecting on proper heifer growth and feeding becomes the most critical factor to achieve this target. Underfeeding of heifers causes stunted growth and can delay or suppress estrus (Brinton et al.,1987). Hence, heifer rations must be balanced to ensure adequate growth rates, to maintain proper body condition, and to achieve desired height and weight. Therefore, well balance nutritious feeding system is essential for maintaining profitable and effective dairy farm.

In conventional feeding, various feedstuff like pasture, concentrate pellet and other agro industrial by products are fed separately in different time intervals. According to the feedstuff, biological and chemical environment of the rumen have to be changed and it will be affected to the ruminal digestion, absorption, rate of passage and finally reduce dry matter intake and lead to nutritional deficiency of weaned heifer (Calsamiglia,2002). However, in conventional feeding system, feed selection is high in heifers which leads to reduced the quantity of the offered

${ }^{I}$ Department of Livestock Production, Faculty of Agricultural Sciences, Sabaragamuwa University of Sri Lanka, Belihuloya, Sri Lanka

${ }^{2}$ Bopaththalawa NLDB Farm, Bopaththalawa, Sri Lanka 
ration. Maekawa et al. (2002) reported that feeding the forage and concentrates separately resulted in cows consuming a high propotion of concentrates than intended, increasing the risk of ruminal acidosis (Beauchemin et al.,2002).

Total Mixed Ration (TMR) can be described as a mixture of both roughages and processed ingredients, formulated and mixed to supply the animal's requirements, in a form that precludes selection. Coppock et al. (1981) compared TMR feeding vs conventional feeding on dary cattle. Their results suggested, TMRI facilitates improvement of the rumen condition, specially keeping less rumen $\mathrm{pH}$ fluctuation and make favorable environment for rumen microbes than the conventional feeding. According to the available literature, ruminal digestion, rate of passage and finally dry matter intake can be improved by TMR feeding in dairy cattle (Bargo et al., 2001; Soriano et al., 2001;Kolver et al.,1998 ). Borland and Kesler (1997) suggested that the use of TMR for young heifers may result in a better balance of nutrient intake by avoiding individual preferences for forage or concentrates.

However, TMR feeding in lactating cows has often been reported in the literature, the way in which effect of TMR feeding in heifers on their weight gain is yet to be elaborated. Therefore the present study was undertaken:

- To investigate the effect of TMR based on Kikuyu grass, Beer pulp, commercial calf starter and commercial mineral mixture on weight gain in weaned Friesian heifers under tropical environment.

- To compare the body weight gain in TMR feeding system and conventional feeding based on the same feed ingredients with the target body weight gain in weaned Friesian heifer.

\section{MATERIALS AND METHODS}

The study was carried out at Bopaththalawa NLDB farm from June to August in 2009 . Three feed ingredients as Wet Brewer's grain (Beer pulp), Kikuyu grass and Commercial concentrates (calf starter ) were used to formulate the TMR which was offered throughout the experimental period.

Eighteen post weaned Friesian heifers age at $111.05 \pm 9.2$ days and weight at $96.6 \pm$ $8.4 \mathrm{~kg}$ were subjected to the experiment and they were randomly assigned to the two feeding systems using nine replicates (9 heifers/feeding system). All the experimental animals were in good health condition prior to the experiment and it was confirmed by a veterinary surgeon. The heifers were housed in 6 pens (3 heifers/one pen ) inside the heifer rearing shed at the Bopaththalawa NLDB farm. Pens were partially enclosed which provided protection from weather and sheltered feed bins from rain. Environment and other physical condition of all the pens were same and the pens consisted of a rough cemented floor area $(4.0 \mathrm{~m} \times 5.0 \mathrm{~m}$; width $x$ length), a cemented standing alley $(0.5 \times 3.0 \mathrm{~m})$ for feeding and a cemented watering bowl $(0.5 \times 0.5 \times 0.5 \mathrm{~m})$.

All the animals had free access to feed as new feed was delivered three times per day at $06.00 \mathrm{~h}, 12.00 \mathrm{~h}$ and $18.00 \mathrm{~h}$ respectively. Water was available adlibitumly to the heifers throughout the day. One week preliminary period was practiced to acclimatize the heifers with the feeding systems. During this period the treatment group was fed with TMR feeding system and the Control Group was fed with the conventional feeding system. Proximate analysis was done to find out the nutritive 
value of each feed ingredient (Table 01). The ration was formulated according to the dry matter requirement ( Table 02 ) of weaned heifer which was based on the recommended target body weight of $600 \mathrm{~g} /$ day $(\mathrm{NRC}, 2001)$.

Table 01: Proximate analysis of nutritive value of each feed ingredient (dry matter basis)

\begin{tabular}{lllllllll}
\hline Ration/ ingredient & $\mathrm{DM} \%$ & $\mathrm{CP} \%$ & $\mathrm{DCP} \%$ & $\mathrm{EE} \%$ & $\mathrm{CF} \%$ & Ash $\%$ & NFE $\%$ & TDN $\%$
\end{tabular}

\begin{tabular}{lcccccccc}
\hline Kikuyu grass & 18.75 & 14.37 & 10.77 & 4.44 & 35.29 & 2.01 & 43.89 & 77.59 \\
& & & & & & & & \\
Brewer's grain & 21.71 & 18.02 & 13.51 & 3.27 & 11.25 & 1.21 & 66.25 & 79.17 \\
& & & & & & & \\
Commercial & 89.01 & 15.24 & 11.43 & 3.74 & 13.25 & 8.58 & 73.45 \\
Concentrates & & & & & & &
\end{tabular}

$\mathrm{DM}=$ Dry matter, $\mathrm{DCP}=$ Digestible crude protein, $\mathrm{EE}=$ Ether extract, $\mathrm{CP}=$ Crude protein, $\mathrm{CF}=\mathrm{Crude}$ fiber, NFE $=$ Nitrogen free exract, $\mathrm{TDN}=$ Total digestible nutrition

The treatment group was fed with Total mixed ration (TMR) including 60\% Kikuyu grass, $20 \%$ Beer pulp and 20\% commercial concentrates (dry matter basis ). The control group was fed with conventional feeding system with the same feed ingredients of the same quantity.

Kikuyu grass were chopped in to $2 \mathrm{~cm}$ pieces and properly mixed with Brewer's grain (Beer pulp) and Commercial concentrate to prepare the TMR for the treatment group. Kikuyu grass with original size (without chopping), Brewer's grain and commercial concentrate were separately given for the control group. Feeding time and frequency were the same for the both group and feed were offered at 06,00h, 12,00h and 18,00h.

\section{Minerals for heifers}

Appropriate amount of commercial mineral mixture (table 03) was added into the TMR for the treatment group and the same quantity was separately given for the control group. Composition of the offered commercial mineral mixture was $\mathrm{Ca}-22 \%$, $\mathrm{P}-11 \%, \mathrm{Na}-12 \%$ and $\mathrm{Mg}-0.8 \%$.

The initial body weights of all experimental animals were measured by using fixed cattle weighing balance at the first day of the experiment. Then body weights were measured for every $7^{\text {th }}$ day (before offering the first meal at 06.00h) throughout the period of study and body weight gains in each animal were recorded weekly.

The average weight gain (ADG) of an individual heifer under each group treatment were analyzed by using the MINITAB Mann-Whitney Test. Effects of dietary treatments in heifers were detected $(P<0.05)$ and the mean separation was conducted by the Mann-Whitney test in MINITAB. 
Table 02: Formulated Ration during each experimental weeks

\begin{tabular}{|c|c|c|c|c|c|c|c|}
\hline Week & $\begin{array}{l}\text { Feed } \\
\text { Ingredient }\end{array}$ & $\begin{array}{r}\mathrm{DM} \\
(\mathrm{Kg}) \\
\text { Dry } \\
\text { matter }\end{array}$ & $\begin{array}{r}\text { FM(kg) } \\
\text { Fresh } \\
\text { matter }\end{array}$ & TDN & $\overline{\mathrm{DCP}}$ & $\mathrm{Ca}$ & $\bar{P}$ \\
\hline & Kikiyu & 1.65 & 8.8 & 1.28 & 0.178 & 0 & 0 \\
\hline \multirow[t]{2}{*}{$1 \mathrm{st}$} & C.P.F & 0.53 & 0.59 & 0.389 & 0.061 & 0.003 & 0.003 \\
\hline & B.Grain & 0.53 & 2.44 & 0.42 & 0.072 & 0 & 0 \\
\hline \multirow[t]{2}{*}{ Total } & & 2.71 & 11.83 & 2.089 & 0.31 & 0.003 & 0.003 \\
\hline & Kikiyu & 1.67 & 8.9 & 1.296 & 0.18 & 0 & 0 \\
\hline \multirow[t]{2}{*}{ 2nd } & C.P.F & 0.56 & 0.62 & 0.411 & 0.064 & 0.004 & 0.003 \\
\hline & B.Grain & 0.56 & 2.57 & 0.443 & 0.076 & 0 & 0 \\
\hline \multirow[t]{2}{*}{ Total } & & 2.79 & 12.09 & 2.15 & 0.32 & 0.004 & 0.003 \\
\hline & Kikiyu & 1.71 & 9.12 & 1.327 & 0.184 & 0 & 0 \\
\hline \multirow[t]{2}{*}{$3 \mathrm{rd}$} & C.P.F & 0.57 & 0.64 & 0.419 & 0.065 & 0.004 & 0.003 \\
\hline & B.Grain & 0.57 & 2.62 & 0.451 & 0.077 & 0 & 0 \\
\hline \multirow[t]{2}{*}{ Total } & & 2.86 & 12.38 & 2.197 & 0.326 & 0.004 & 0.003 \\
\hline & Kikiyu & 1.75 & 9.33 & 1.358 & 0.188 & 0 & 0 \\
\hline \multirow[t]{2}{*}{ 4th } & C.P.F & 0.59 & 0.66 & 0.433 & 0.067 & 0.004 & 0.003 \\
\hline & B.Grain & 0.59 & 2.71 & 0.467 & 0.08 & 0 & 0 \\
\hline \multirow[t]{2}{*}{ Total } & & 2.93 & 12.7 & 2.258 & 0.336 & 0.004 & 0.003 \\
\hline & Kikiyu & 1.8 & 9.6 & 1.397 & 0.194 & 0 & 0 \\
\hline \multirow[t]{2}{*}{5 th } & C.P.F & 0.6 & 0.67 & 0.441 & 0.069 & 0.004 & 0.003 \\
\hline & B.Grain & 0.6 & 2.76 & 0.475 & 0.081 & 0 & 0 \\
\hline \multirow[t]{2}{*}{ Total } & & 3 & 13.03 & 2.312 & 0.344 & 0.004 & 0.003 \\
\hline & Kikiyu & 1.84 & 9.81 & 1.428 & 0.198 & 0 & 0 \\
\hline \multirow[t]{2}{*}{ 6th } & C.P.F & 0.61 & 0.68 & 0.448 & 0.07 & 0.004 & 0.003 \\
\hline & B.Grain & 0.61 & 2.8 & 0.483 & 0.082 & 0 & 0 \\
\hline \multirow[t]{2}{*}{ Total } & & 3.07 & 13.29 & 2.359 & 0.35 & 0.004 & 0.003 \\
\hline & Kikiyu & 1.89 & 10.08 & 1.466 & 0.204 & 0 & 0 \\
\hline \multirow[t]{2}{*}{$7 w k$} & C.P.F & 0.63 & 0.7 & 0.463 & 0.072 & 0.004 & 0.003 \\
\hline & B.Grain & 0.63 & 2.9 & 0.499 & 0.085 & 0 & 0 \\
\hline \multirow[t]{2}{*}{ Total } & & 3.15 & 13.68 & 2.428 & 0.361 & 0.004 & 0.003 \\
\hline & Kikiyu & 1.98 & 10.56 & 1.536 & 0.213 & 0 & 0 \\
\hline \multirow[t]{2}{*}{$8 w k$} & C.P.F & 0.66 & 0.74 & 0.485 & 0.075 & 0.004 & 0.004 \\
\hline & B.Grain & 0.66 & 3.04 & 0.523 & 0.089 & 0 & 0 \\
\hline Total & & 3.3 & 14.34 & 2.544 & 0.378 & 0.004 & 0.004 \\
\hline
\end{tabular}

Table 03: Mineral composition of the diet for a weaned heifer.

\begin{tabular}{|c|c|c|c|c|c|c|}
\hline & \multicolumn{2}{|c|}{$1^{\text {st }}-2^{\text {nd }} w k$} & \multicolumn{2}{|c|}{$3-5 \mathrm{wk}$} & \multicolumn{2}{|c|}{$6-8 \mathrm{wk}$} \\
\hline & $\mathrm{Ca}$ & $\mathrm{P}$ & $\mathrm{Ca}$ & $P$ & $\mathrm{Ca}$ & $\mathrm{P}$ \\
\hline Kikuyu grass (g) & - & - & - & - & - & - \\
\hline Brewer grain $(\mathrm{g})$ & - & - & - & - & - & - \\
\hline C.P.F (g) & 3.0 & 3.0 & 4.0 & 3.0 & 4.0 & 4.0 \\
\hline C.M.M total (g) & 64.0 & 64.0 & 64.2 & 64.2 & 64.3 & 64.3 \\
\hline Ca, P from C.M.M & 14.01 & 7.04 & 14.12 & 7.06 & 14.14 & 7.07 \\
\hline Ration composition (Total) (g) & 17.01 & 10.04 & 18.12 & 10.06 & 18.14 & 11.07 \\
\hline Actual Animal Requirement (g) & 17.0 & 9.0 & 18.0 & 9.0 & 18.0 & 10.0 \\
\hline
\end{tabular}

C.P.F $=$ commercial pellet feed, C.M.M $=$ commercial mineral mixture 


\section{RESULTS AND DESCUSSION}

\section{Live body weight and target bodyweight}

The relationship between target body weight and experimental body weight of weaned heifers in treatment and control group showed respectively in figure 01 and figure 02 .According to the figure 01, most of the treatment group heifer's live body weight has been attained the target body weight than the heifers in the control group which is showed in Figure 02. Except R4 and R9 heifers in treatment group (TMRs),others live body weight have been attained to the target body weight and in control group (conventional feeding) most heifers body weight were not reached to the target body weight except R1 and R4 heifers body weight.

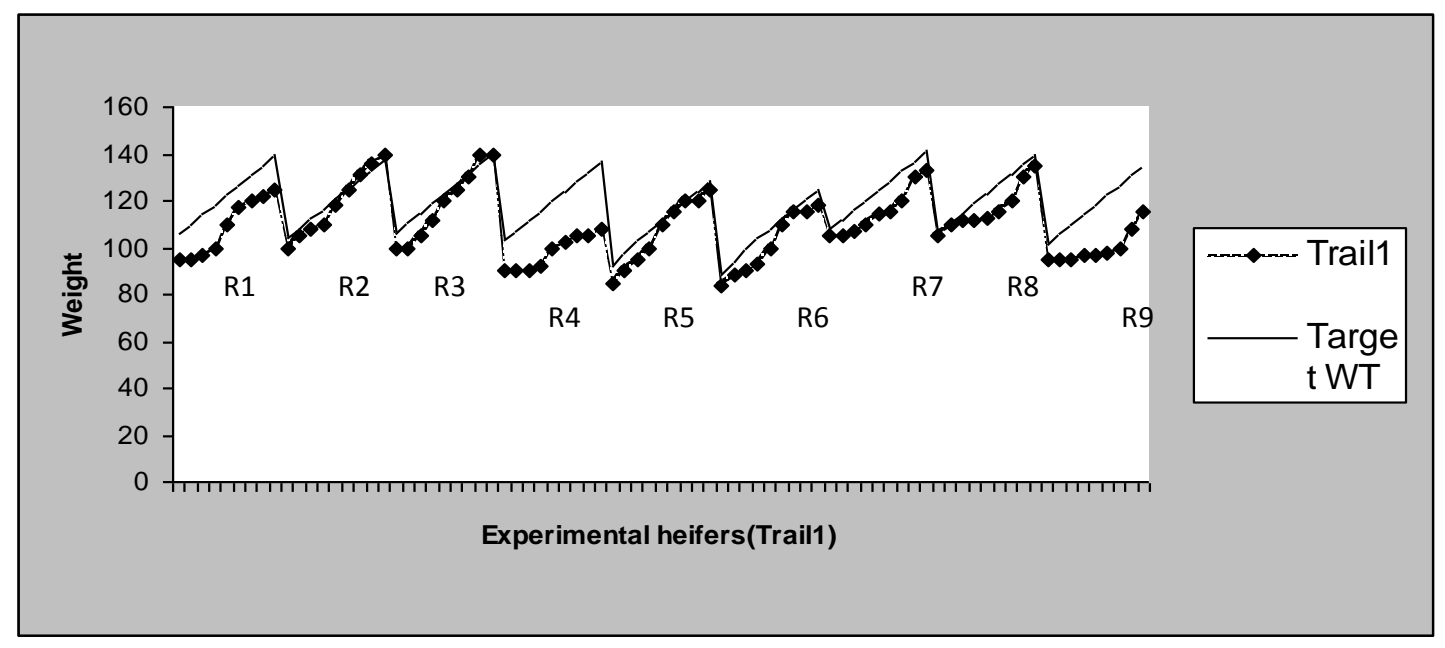

Figure 01: Live body weight of individual heifers in TMR feeding system with the target body weight

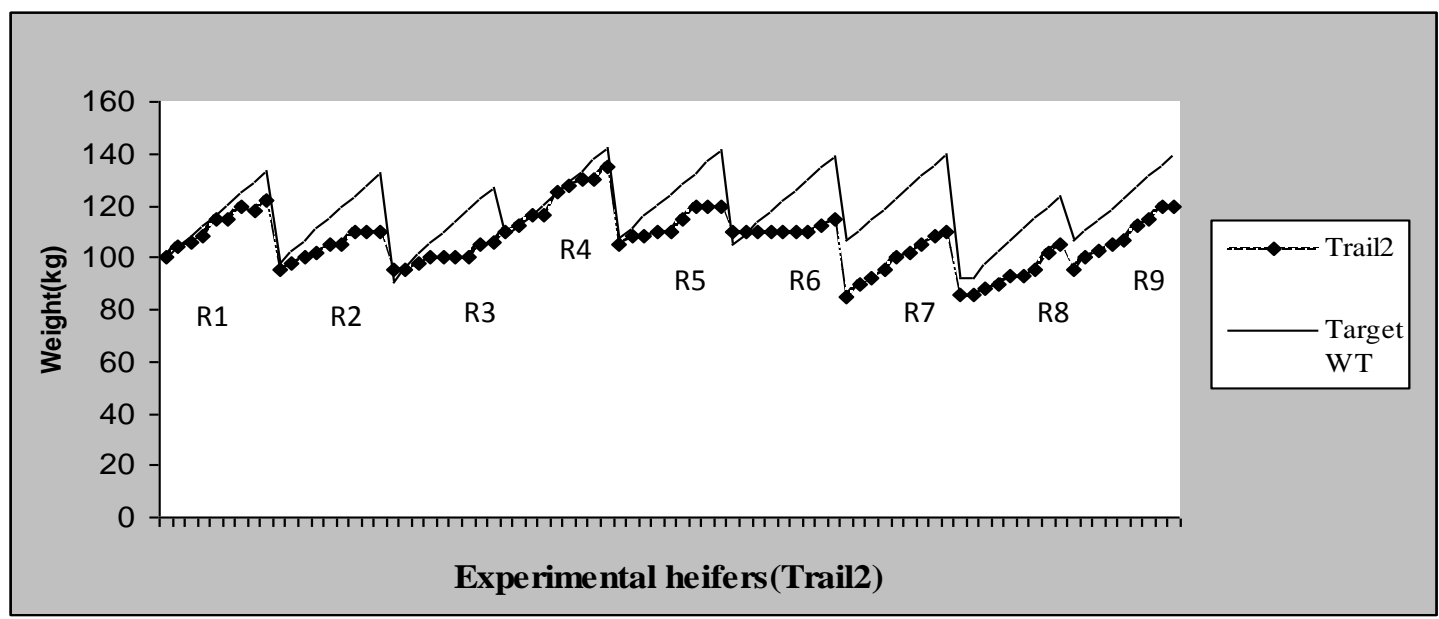

Figure 02: Live body weight of individual heifers in conventional feeding system with the target body weight 
Average daily weight gain (ADG) of individual experimental heifers

Figure 03 shows, AVG of individual experimental heifers. ADG of 4 heifers in Treatment group(TMR) were attained the recommended ADG of $0.60 \mathrm{~kg}$ and no heifers in the control group attained to this level even though they were fed with the same amount of feed ingredients that used for TMRs. R4 in TMR feeding system and R6 in conventional feeding system showed lowest ADG values as they had been suffered from severe diarrhea cases since $3^{\text {rd }}$ to $5^{\text {th }}$ weeks of the experiment period. According to the live body weight gain of each experimental heifer, the average daily weight gains under two different treatments were calculated for every week (Figure 04). In statistical analysis, significance was declared when $P<$ 0.05.The differences of ADG in the two groups were highly significant.

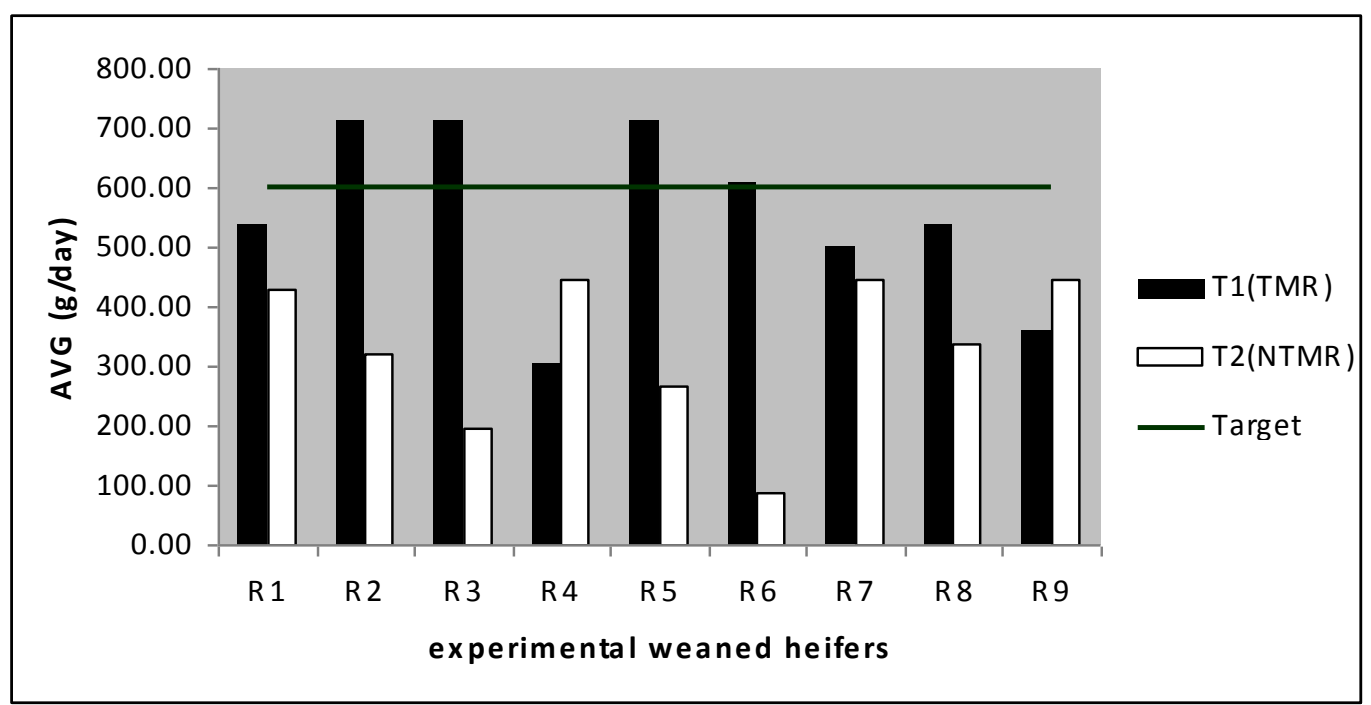

Figure 03: ADG of individual heifers in two different feeding systems with the target AVG (NRC)

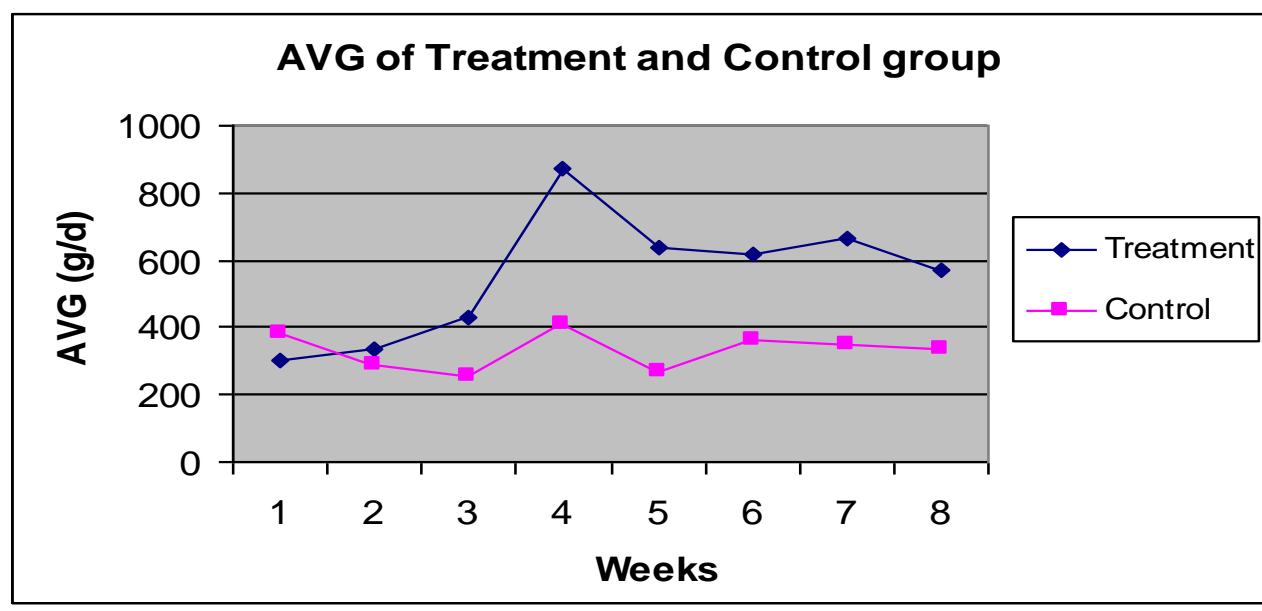

Figure 04: A comparison of average daily weight gain in heifers in two different feeding systems 
Treatment group shows the higher ADG value $(0.55 \mathrm{~kg} / \mathrm{day})$ which was closer to the recommended ADG value. Heifers allowed to the conventional feeding system with the same type and amount of feed ingredients were showed lower ADG value than the TMR fed group and it was only $0.33 \mathrm{~kg} /$ day.

Formulated ration with the Kikuyu grass, commercial pellet feed and brewer's grain (beer pulp) have supported the recommended ADG value of $0.60 \mathrm{~kg} / \mathrm{day}$. Especially during the $4^{\text {th }}, 5$ th, 6 th and $7^{\text {th }}$ week periods, treatment group heifers were able to achieve this recommended ADG value. The growth rates of the control group heifers did not achieve the recommended value during the experimental period even though they, too, were fed with the same amount of Kikuyu grass, commercial pellet feed, brewer's grain and commercial mineral mixture.

Low performing rumen function such as fermentation, digestion, optimum $\mathrm{pH}$, absorption, rate of passage, and finally lower dry matter intake will be resulted due to the intake of uneven feed stuff practicing with conventional separate feeding. With regarding TMR feeding, each mouthful containing same feed materials and its are evenly come to the rumen at every feeding time and it will facilitate to improve rumen condition specially keeping less rumen $\mathrm{pH}$ fluctuation and to make favorable environment for rumen microbes than the conventional feeding. (Bargo et al., 2001; Soriano et al., 2001; Kolver et al., 1998).

Optimum fiber digestion and utilization in the rumen can be achieved Practicing with proper TMRs feeding programme (Mould and Ørskov, 1983) because of it will facilitate to maintain optimum $\mathrm{pH}$ in the rumen with keeping less $\mathrm{pH}$ fluctuation. Palatability is also a concern, especially in conventional feeding systems. Certain feedstuffs and additives may depress intakes of concentrates when fed conventionally compared to a total mixed ration (TMR). When feeding rations with low digestibility, rumen fill is quickly achieved. These rations are digested slowly and, to a lesser extent, pass out of the rumen at a slower rate. (Tamminga et al., 1979; Loerch, 1990). When rumen fill occurs, a signal is sent to the brain stem to stop intake as part of the overall process of intake regulation.

Clearly, in conventional separate feeding the animals were preferentially sorting for the highly palatable feed components and against the longest forage particles. (Hoffman et al., 2006). Therefore wastage of forages was high in conventional feeding practices. Ultimately ingestion of fiber also less in conventional feeding practices than the TMRs. Fiber plays significant role in rumen making with volatile Fatty acid (VFA).So formation of VFA in rumen is also less in conventional feeding than TMRs (Satter et al,1964). Roughages that are used to TMRs cut in to smaller pieces and it lead to improve digestibility and reduced selecting behavior of the heifers. Reduced forage particle size decreases the time spent chewing and causes a trend toward decreased ruminal $\mathrm{pH}$ (Woodford and Murphy,1988).As particle length declines, cows spend less time chewing, thereby decreasing the volume of saliva produced that acts to buffer ruminal contents (Grant et al.,1990).

In this study Wet brewer's grain was used as a feed ingredient to reduce the cost of ration. Wet brewer's grain is often used as the main ingredients of TMRs with suitable roughages (Abe, 2000) and it is a most common by product which is used to feed milking herd.( Conrad and Rogers ,1977). In addition of nutritional benefit of brewer grain, it contains large number of yeast (Saccharomyces spp.) and they 
supported rumen microbes (Solange and Mussatto,2008).However there were no more data for heifer ration containing wet brewer grain. According to the results of this study the effectiveness of wet brewer grain in TMRs for weaned heifers was satisfactory. But additional research needs to evaluate the effect of feeding of wet brewer's grain in growing Friesian heifers under tropical environment.

During the $1^{\text {st }}, 2^{\text {nd }}$, and $3^{\text {rd }}$ weeks, the ADG of the treatment group heifers have been increased gradually. But ADG did not attained the recommended ADG of $0.60 \mathrm{~kg}$ during the first three weeks. The reason may be the poor acclimatization and density of rumen microbial population to the new feed as prior to the experiment they were fed with Kikuyu grass and commercial pellet feed under conventional separate feeding. During the $1^{\text {st }}$ week of the experiment, the ADG values of the treatment and control group were $301.58 \mathrm{~g} / \mathrm{d}$ and $380.95 \mathrm{~g} / \mathrm{d}$ respectively.It seems that the newly introduced total mixed ration was not so common for heifers in the treatment group than the conventional separate feeding which have been practicing to feed the heifers prior to the experiment.Therefore, adaptability and acceptability of TMR feed were poor during the $1^{\text {st }}$ and $2^{\text {nd }}$ week in the treatment group.But it was not affected to the control group heifers as they were exposed to conventional feeding system prior to the experiment. Thist may be the reason to shave a lower growth rate in the treatment group heifers than in the control group heifers during the $1^{\text {st }}$ week of experiment period.

The data showed a significant value in ADG in TMR feeding group than the control group for the $4^{\text {th }}$ and $5^{\text {th }}$ weeks of period. In the $4^{\text {th }}$ week of the experiment period, ADG values of the treatment and control group were $872.95 \mathrm{~g} / \mathrm{d}$ and $412.70 \mathrm{~g} / \mathrm{d}$ respectively. According to the
Figure 1, the ADG of the two different feeding groups were significantly increased during the $4^{\text {th }}$ week than the prior experimental weeks. There was a heavy rainy weather condition throughout the $1^{\text {st }}, 2^{\text {nd }}$ and half of the $3^{\text {rd }}$ weeks of period. During this period moisture level of Kikuyu grass would have increased and it was negatively affected for the final quality of the feed rations. As well as heavy rain may be stress for all the experimental heifers and it may be badly affected to the dry matter intake (DMI).

However during the $4^{\text {th }}$ week all the experimental heifers were comforted by better weather condition with proper sunlight. Anthelminthic drugs were given to all the experimental heifers at the $3^{\text {rd }}$ day $(17 / 7 / 09)$ in the $3^{\text {rd }}$ week and worms were appeared in the dung materials at the $5^{\text {th }}$ day in the 3 rd week. This may be the reason to increase body growth and ADG of all the experimental heifers both in the treatment and control group.

\section{CONCLUTIONS}

The combination of wet brewer grain (WBG), Kikuyu grass (K),Commercial pellet feed (CPF) and commercial mineral mixture in TMR resulted higher body weight gain in heifers, than the conventional separate feeding system with the same ration. The growth rate of 553.54 $\pm 152.06 \mathrm{~g} /$ day were sufficiently met when heifers consumed the TMR. But in the conventional separate feeding system, heifers achieved growth rate of $331.34 \pm$ $127.57 \mathrm{~g} / \mathrm{day}$. Therefore, TMRs may help to reduce the feed wastage and enable producers to target caloric intake for desirable weight gain and development in weaned heifers. Weaned heifers having a $553.54 \pm 152.06 \mathrm{~g} /$ day of growth rate, can be bred in 15-18 month of age and there is a possibility of achieving first calving in 24-27 month of age. 


\section{ACKNOWLEDGEMENT}

This study was fully funded by Bopaththalawa NLDB farm. The authors gratefully acknowledge the farm manager, Mr. K.A.G Pathmasiri and the staff for their invaluable support extended throughout this study.

\section{REFERENCES}

Abe,A.(2000). Food By-products and Total Mixed Ration Center. Snow Brand Milk Products Co. Ltd., Sapporo, Hokkaido, Japan.

Bargo,F.L.,D.Muller, J.E.Delahoy and T.W.Cassidy.(2002).Performance of high producing dairy cows with three different feeding systems combining pasture and total mixed rations. Journal of Dairy Sci.85,pp:2960-2975.

Beauchemin,K.A.,M.Maekawa and D.A.Christensen.(2002).Effect of diet and parity on meal patterns of lactating dairy cows. Canadian journal of Animal Science,82,pp:215 223.

Borland,K. and E.M.Kesler.(1979).Complete ration for Holstein calves 8 to 18 weeks of age.Journal of Dairy Science,62,pp:304 - 309.

Calsamiglia,S.,A.Ferret, and M.Devant.(2002). Effects of $\mathrm{pH}$ and $\mathrm{pH}$ fluctuations on microbial fermentation and nutrient flow from a dual-flow continuous culture system. J. Dairy Sci. 85,pp:574-579.

Conrad, H. R. and J. A. Rogers. (1977). Comparative nutritive value of brewers wet and dried grains for dairy cattle. U.S. Brewers Assoc. Feed Conf., St. Louis, MO. pp:26-33

Coppock,C.E.,C.G. Woelfel and R.L.Belyea.(1981).Forage and feed testing programmesproblumes and opportunities. J. of Dairy Science.64,pp:1625-1632

Hoffman, P.C., C. R. Simson, and K. J. Shinners. (2006). Evaluation of hay feeding strategies on feed sorting behavior of dairy heifers fed mock lactation diets. Prof. Anim. Science, 22,pp:71-79.

Grant,R.J.,V.F.Colenbrander and D.R.Mertens.(1990).Milk fat depression in dairy cows: Role of particle size of alfalfa hay. Journal of Dairy Science,73,pp:1823 - 1833

Kolver,E.S., and L.D.Muller.(1998). Performance and nutrient intake of high-producing Holstein cows consuming pasture or a total mixed ration. Journal of Dairy Science, 81,pp: 1403-1411

Loerch,S.C.(1990). Effects of feeding growing cattle high-concentrate diets at a restricted intake on feedlot performance. Journal of Anim. Science, 68,pp:3086-3095.

Maekawa,M., k.A.Beauchemin and D.A.Christensen.(2002).Effect of concentrates level and feeding management on chewing activities, saliva production and ruminal $\mathrm{pH}$ of lactating dairy cows. Journal of Dairy Science,85,pp:1165 -1175.

Mould,F.L., and R.E.Ørskov.(1983). Manipulation of rumen fluid $\mathrm{pH}$ and its influence on cellulolysis in sacco, dry matter degradation and the ruminal microflora of sheep offered either hay or concentrate. Anim. Feed Sci. Technology, 10,pp:1-14.

National Research Council.(2001).Nutrient Requirement of dairy cattle. Natl.Acad.Sci., Washington, DC

Satter,L.D,J.W.Suttie and B.R.Raumgardt.(1964).TMR for Dairy cattles. Departments of Dairy Science and Biochemistry, University of Wisconsin, Madison

Solange I. Mussatto (2008). Total refuse of brewers spent grain in chemical and biotechnological processes for the production of added-valve compound, Institute for 
Biotechnology and Bioengineering, Centre of Biological Engineering, University of Minho, Campus de Gualtar, pp: 4710-057.

Soriano,F.D.,C.E.Polan, and C.N.Miller.(2001). Supplementing pasture to lactating Holsteins fed a total mixed ration diet. Journal of Dairy Science, 84,pp:2460-2468.

Tamminga,S.C.,J. van der Koelen and A.M.van Wauren.(1979). Effects of the level of feed intake on nitrogen entering the small intestine of dairy cows. Livestock Production Science, 6,pp:255-262.

Woodford,S.T. and M.R.Murphy.(1988).Effect of forage physical form on chewing activity, dry matter intake and rumen function of dairy cows in early lactation. Journal of Dairy Science,71,pp:674-686 